\title{
Oyster farming in Japan
}

\author{
M. FujIYA \\ The Nansei Regional Fisheries Research Laboratory; \\ Maruishi, Obno-cho, Saeki-gun, Hiroshima Pref., Japan
}

KURZFASSUNG: Austernzucht in Japan. In Japan nahm die Austernzucht ihren Anfang zu Beginn des 17. Jahrhunderts. Seither sind die Zuchtverfahren wesentlich verbessert und wissenschaftlich überprüft worden. Die wichtigste in Japan kultivierte Auster ist Crassostrea gigas. Der gegenwärtige Stand der Methodik, Produktivität und Wirtschaftlichkeit der japanischen Austernzucht wird dargelegt. Einige biologische und zivilisatorische Schadensgefahren sowie zukünftige Probleme, die sich bezïglich einer Intensivierung der Austernzucht ergeben, werden erörtert.

\section{INTRODUCTION}

The oyster is one of the most popular farming organisms in Japan (Fig. 1). The history of oyster farming is quite long. A fisherman, who lived in Hiroshima sometime between 1624 and 1643, one day noticed an oyster attached to a rock. He placed rocks in the shallow water to see if oysters would attach to them, and they did. He also observed oysters attached to bamboo branches which were being used in the construction of fish traps. These two observations by the fisherman are believed to be the basis for the ancient methods of oyster farming using stones and bamboo.

After this, generation by generation, the method was modified, as new information was obtained by fishermen and scientists, and modern methods were developed.

The Inland Sea, especially around Hiroshima, is a particularly good place for oyster farming, and $60-65 \%$ of the total oyster production of Japan (45,000 tons shucked meat in 1967) is produced in this area.

There are 13-30 species of oysters along the coast of Japan, but the exact number of species is not known. The species which are commercially valued are: Crassostrea gigas ("Magaki"), Ostrea denselamellaris ("Itabogaki"), Crassostrea rivularis ("Suminoegaki"), Crassostrea nippona ("Iwagaki"), Ostrea edulis (Europian oyster), Crassostrea angulata (Portuguese oyster) and Crassostrea virginica (American oyster).

Among these valuable species, Crassostrea gigas is the most important one. Its growth rate is higher than that of the other species and it is believed that the taste is also better. Therefore, most of the oyster growers of Japan use this species. There are two races of this species, a northern and a southern race, but their ecological and physiological characteristics are only slightly different. 
As Crassostrea gigas is the most common species, the biology and farming procedure of this oyster are discussed in this paper.

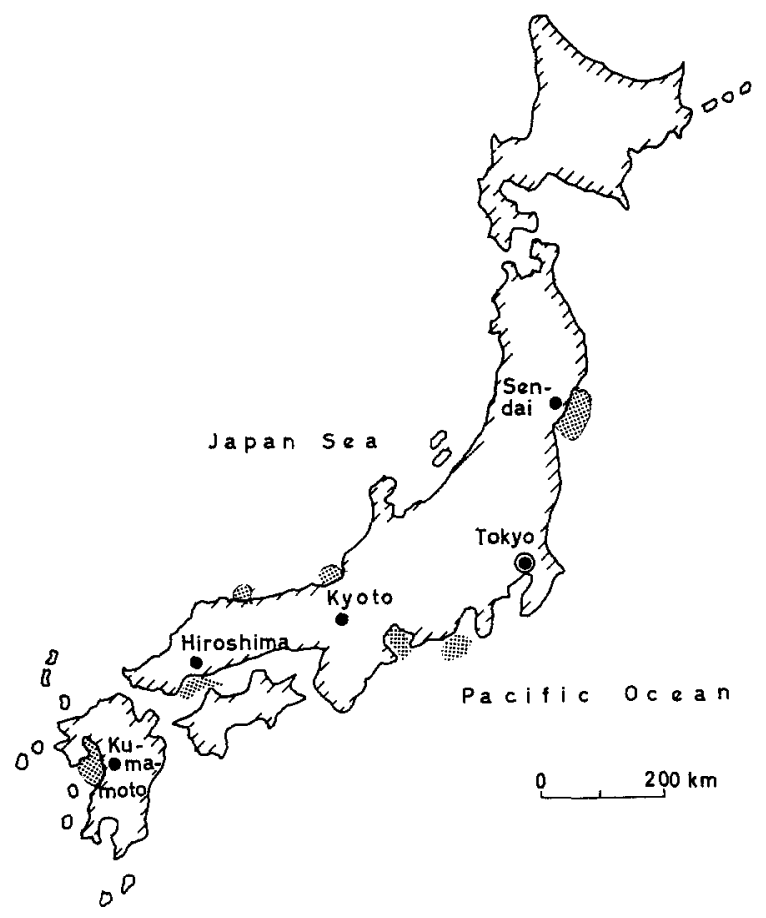

Fig. 1: Oyster farming grounds (spotted areas) in Japan

\section{BIOLOGY OF CRASSOSTREA GIGAS}

\section{Spawning and developmental conditions}

Molluscs such as the oyster cannot move to find optimum living conditions. In nature, therefore, their distribution is limited and greatly influenced by environmental conditions.

With the autumnal decrease of water temperature deposition of glycogen starts, and this is especially important for maturation, because glycogen is a main source of energy for the oyster. Therefore, the suitable winter environmental conditions are necessary to produce the best oysters for spawning purposes.

The gonads are completely mature between May and June, and in this period spawning is easily stimulated both physically and chemically (SATO 1967).

In nature, the optimum water temperature for spawning is about $20^{\circ} \mathrm{C}$, and spawning is inhibited when the salinity of the water goes down below $27 \%$ \% (SATo 1967). The rapid increase of water temperature, immediately after the rainy season, stimulates spawning. 
During spawning, the eggs are discharged from the ovary into the mantle cavity, then, the aductor muscle undergoes a series of rythmic contractions, causing the discharge of the egg through the opening of the mantle into the sea. The spermatozoa are released from between the partially opened valves of the shell and fertilization occurs in the sea.

The development of the zygote is greatly influenced by water temperature. The optimum temperature was determined for the early developmental stages of this species by observations of larval growth up to the formation of the larval shell; the rate of development of normal and abnormal larvae under various water temperature conditions has also been studied (CAHN 1950).

Optimum temperature for the development of Crassostrea gigas lies between $23^{\circ}$ and $25^{\circ} \mathrm{C}$. The maximum and minimum limits within which the zygote can develop to the shelled larval stage are $15^{\circ}$ and $30^{\circ} \mathrm{C}$ respectively. The percentage of eggs developing to the shelled stages has a tendency to decrease sharply at temperatures above the optimum, and decrease slowly at temperatures below the optimum (CAHN 1960, Galtsoff 1964, Sato 1967).

Under optimum conditions of salinity, 23-28\%, a high percentage of the fertilized eggs undergo cleavage and reach normal developmental stages. In water having unsuitable salinity, especially in the high salinity range, the blastomeres of the embryo have a marked tendency to separate from one another. If the salinity was either too high or too low, many eggs are fertilized, but no cleavage occurs.

The salinity ranges suitable for development are not the same at different temperatures even for a single species of oyster; the salinity tolerance range is greater at lower temperatures than higher temperatures. The formation of the larval shell is retarded both by low temperature and low salinity.

\section{Reproduction}

While in the ovary, the immature egg is a pear-shaped body attached to the tissue of the ovary by a stalk-like structure. When the mature egg is extruded into the seawater it becomes a sphere. It has a transparent egg membrane and varies in diameter from 0.045 to $0.058 \mathrm{~mm}$. The surface of the egg is smooth, and it has no micropyle. The contents of the eggs are transparent and have no color. The number of eggs laid annually by $C$. gigas is dependent upon living conditions, and the average is 500,000-100,000,000 (SA to 1967).

The eggs can remain alive in seawater for a brief period without fertilization; their viability depends on the environmental conditions, especially water temperature and salinity. Under optimum conditions (salinity: 23-28\%, water temperature: $27^{\circ} \mathrm{C}$ ) the eggs can live for about $15 \mathrm{~h}$ after discharge.

The spermatozoa of Crassostrea gigas are $0.078 \mathrm{~mm}$ in total length. Their rounded head has a diameter of $0.0073 \mathrm{~mm}$. When fully active, the sperm darts through the water at a speed of about $0.05 \mathrm{~mm}$ per second, but maximum performance does not continue for long periods of time. When activity declines, it dies immediately. Under best conditions spermatozoa can suvive for about $15 \mathrm{~h}$ without union with an egg (CAHN 1950, Sato 1967). 
At a water temperature of $25^{\circ} \mathrm{C}$ development proceeds as follows: 50-60 min -1 st polar body appears on the ventral side; $1 \mathrm{~h} 40 \mathrm{~min}-1$ st cleavage; $2 \mathrm{~h}-2$ nd cleavage; $3 \mathrm{~h}$ - mulberry (morula) stage; 4-5 h - gastrula stage; $10-20 \mathrm{~h}$ trochophore stage; 24-30 h - straight-hinge stage; 3-4 days - umbo stage; 10-15 days - fixation stage; $15-20$ days - spat.

\section{Food}

At the larval stage, small plankton with a diameter of less than $10 \mu$ and organic suspended matter of about the same size are taken.

Adults feed on detritus and micro-organisms like phytoplankton (such as diatoms) and zooplankton (such as flagellates).

\section{FARMING PROCEDURE \\ Farming field}

Suitable farming sites require the following conditions:

(a) The farming area must be protected by nature or by simple construction against violent wind and wave actions.

(b) Adult oysters, which produce the spawn, must be present in nearby waters in sufficient numbers to insure adequate rates of reproduction.

(c) Tidal and/or current flow must be sufficient to change the water of the area completely and frequently.

(d) The oceanographic conditions of the areas must be suitable for oyster growth, especially the salinity and water temperature.

(e) The water must contain adequate nourishment for plankton production and should contain abundant phytoplankton suitable as food for oysters and their larvae.

(f) The area must be protected against industrial wastes and/or sewage. Molluscs concentrate metallic elements in their body, which may be harmful to humans, even if the concentration in the water is low and no effect is observed on the shellfish (FuJrya 1965).

(g) The water of the area should be clean from a sanitary point of view.

\section{Spat collection}

\section{Season}

The larva of Crassostrea gigas begins to swim several hours after fertilization, and leads a planktonic life for 10-14 days. When the time for attachment arrives, the "collectors" must be already in the water to attract the larvae. It is most important that oyster growers put the collectors in the water at the correct time. If they put them in too early, the surface of the collectors will be covered with barnacles, mussels and 
other animals and/or seaweeds and, quite frequently, mud; as a result, spat collection would be unsuccessful. The time of placing the collectors must be closely correlated with the beginning of the major setting period.

In order to give the best results, the prefectural and municipal Fisheries Experimental Stations are taking daily records of changes of water temperature and are counting samples of swimming oyster larvae collected by plankton nets to determine the best time for the oyster growers. They can then place their collectors in the water at the right time and thus assure greatest settling efficiency.

Generally, just after the rainy season when the water temperature rises over $20^{\circ} \mathrm{C}$, good spawning can be expected.

\section{Placing the collectors}

Oyster larvae are free-swimming plankton organisms which prefere the near-surface water. The water layer which contains maximum numbers of larvae is very narrow; hence, placing the collectors in the best possible position to allow these swimming larvae to settle is extremely important. The collector must be placed where the tidal current carries the larvae back and forth (Fig. 2).

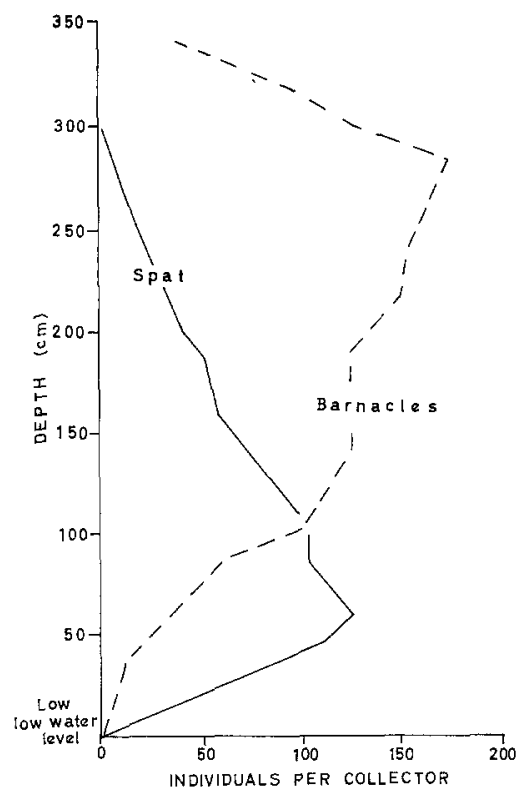

Fig. 2: An example of the vertical distributions of oyster spat and barnacles. (After CAHN 1950)

\section{Type of collectors}

Previously, bamboo, tree branches, roof tiles and stones were used, but now shells and/or plastic plates are employed as collectors. In most cases, scallop (Pecten) shells 
are used for spat collecting. Large scale spat collection is accomplished by suspending wires ("ren") of 1 to $2 \mathrm{~m}$ length, which bear many scallop shells, from a bamboo frame work driven into the bottom. The wires are hung across the frame work by their middle, thereby forming a double collector string of about $1 \mathrm{~m}$ or less in length. The wire is No. 16 galvanized, made especially for oyster farming, and is generally called "half-steel" wire.

The collectors are pierced and strung on the wire about 1-2 $\mathrm{cm}$ apart with bamboo or plastic spacers between the shells. Although plastic spacers cost about three times as much as bamboo, they are becoming increasingly popular because they can be used repeatedly while bamboo must be replaced annually.

Recently, a new form of spat collector is being used on a large scale experimental basis in the Hiroshima area, both by biologists at the laboratory and by some of the commercial oyster growers. The new collector consists of hexagonal plastic netting ("netron" produced by Dupont) which has a rigid, rubbery consistency and a mesh size of about $5 \mathrm{~cm}$. It is cut into strips about $15 \mathrm{~cm}$ wide and $5-10 \mathrm{~m}$ long which are suspended horizontally from the collecting racks; they hang vertically from the raft while the oysters are in the growth field. A good set consists of about 20-30 good spat per shell collector.

When oysters reach seed size (1-1.5 cm; within about 1 month) the collectors are removed from the collecting racks, unstrung from the wires, cleaned, and restrung on new, heavier wires (No. 13) with bamboo or plastic spacers about $20 \mathrm{~cm}$ in length; then the wires are hung on the rafts for the oysters to continue growth to market size.

\section{Growing method}

Up to about 10 years ago, sowing, stone, and bamboo culture were also used, but now hanging methods are usually applied.

The following 3 types of hanging methods have been developed: raft method, longline method and rack method.

Raft and rack methods are most important and most abundant in the southern part of Japan; the long-line method is common along the coast of Northern Japan, because, in this area, the geographical conditions are more suitable for long-line techniques.

\section{Raft method}

This method is used especially in the Inland Sea (Fig. 3). The rafts used for oyster farming are standarized in size and construction; they are made from $10-15 \mathrm{~cm}$ diameter bamboo or wood (cedar) poles (lashed with wire) in two layers at right angles to each other and with the poles $30-60 \mathrm{~cm}$ apart. The standard raft in the Inland Sea, for example, is about $16 \times 8 \mathrm{~m}$ in size and carries $500-600$ wire rens.

The rafts are buoyed by hollow, concrete drums; tarred wooden floats, or specially constructed styroform cylinders about the size of a 50 gallon drum. Styroform cylinders have increasingly replaced the other float types and are now used in all 
newly constructed rafts. As the growth of the oyster proceeds, and their weight increases, additional floats are added as required. The styroform floats are usually encased in a large polyethylene bag to protect them from barnacles and other organisms.
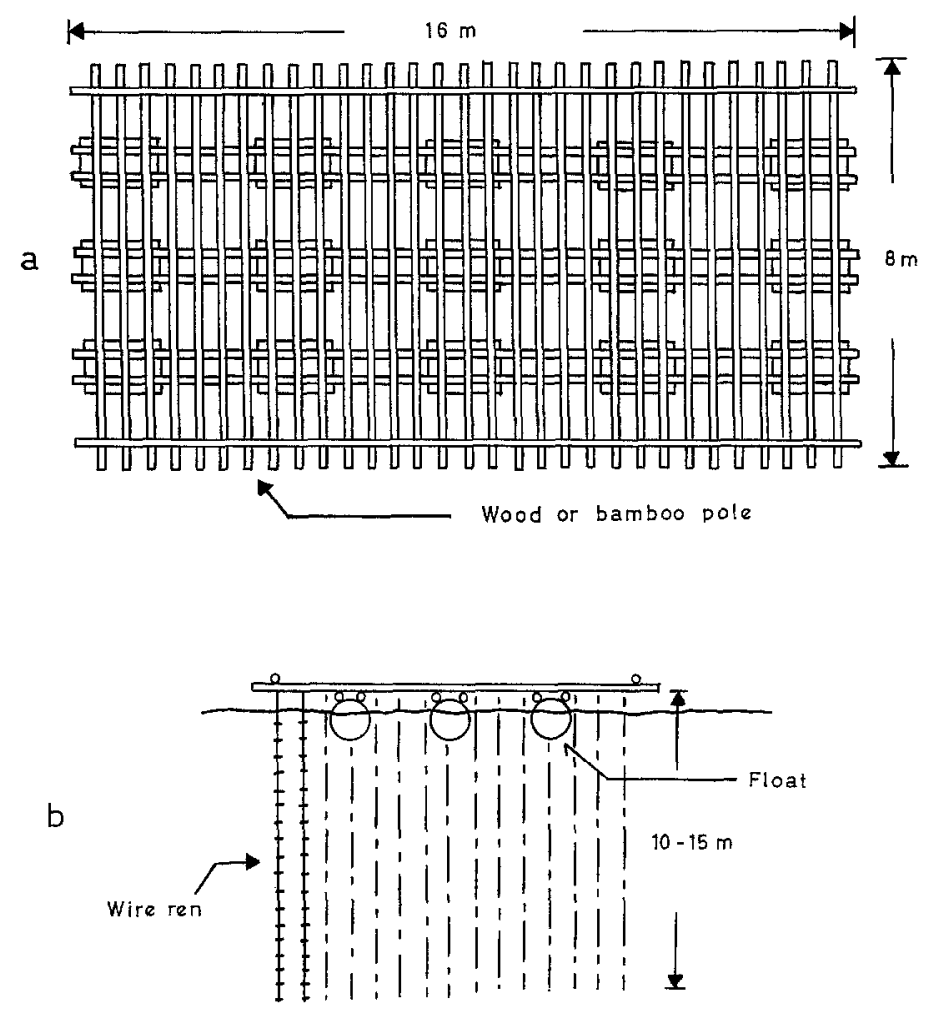

Fig. 3: Raft method for oyster farming. Top view (a) and side view (b)

Rafts are commonly laid out in rows 5-10 m apart, tied together with lines and anchored at each end of the line. Ten or more rafts are tied together. In other cases, two rafts are individually anchored. The rafts are left in the water, but may be moved inshore during spring for maintenance purposes. Their average life is about 5 years.

\section{Long-line method}

The long-line method is a modification of the hanging method developed along the northern parts of Japan (Figs. 4 and 5). It was first applied in 1947. The long-line technique resists wind and waves, and hence is more suitable for open sea areas than the other 2 methods.

The basic structure of a unit of this type consists of a series of wooden barrels or metal drums used as floats and arranged in rows. Each end of the line is anchored with 
2 or 3 anchors; sometimes also the middle portion of the line is anchored. The length of the line is usually $70-75 \mathrm{~m}$ and there are about 10-12 floats. Each line is paralleled by two straw ropes (tarred rice ropes of $6 \mathrm{~cm}$ diameter) about $60 \mathrm{~cm}$ apart.

a

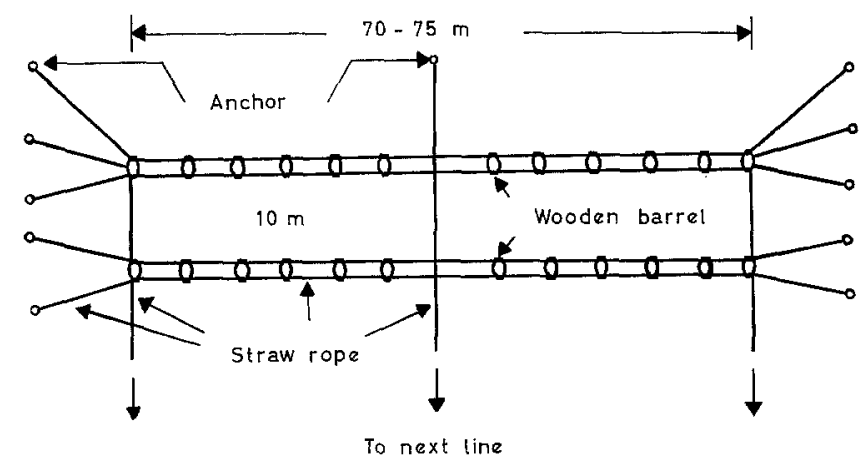

b

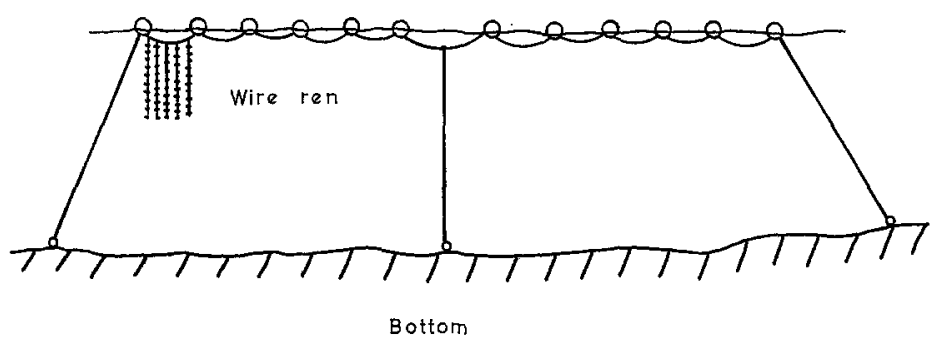

Fig. 4: Long-line method for oyster farming. Top view (a) and side view (b)

At each end of the parallel long-lines, series of vertical ropes are suspended (tarred rice ropes of $4 \mathrm{~cm}$ diameter) and from 7.5 to $10 \mathrm{~m}$ length, depending on water depth. This is done after the collector shells with the seed oysters have been placed on the ropes for further growth. The vertical ropes (Fig. 5) do not reach the sea bottom at any time and are hung about $30 \mathrm{~cm}$ apart along the supporting lines between the barrels.

\section{Rack method}

The rack method is a shallow water modification of the hanging method (Fig. 6). On the structure of the rack, poles (usually bamboo, 2-5 $\mathrm{m}$ long) are driven into the ground. These vertical poles are connected by horizontal poles at any spacing desired. Usually, the vertical poles are aligned with each other, in both directions, with horizontal crossbracing. The wire rens are hung from these horizontal poles. The length of wire ren depends on the depth of the water. 
The rack method has been used for oyster fattening, but at present is mostly applied for seed oyster culture and for hardening of young oysters.

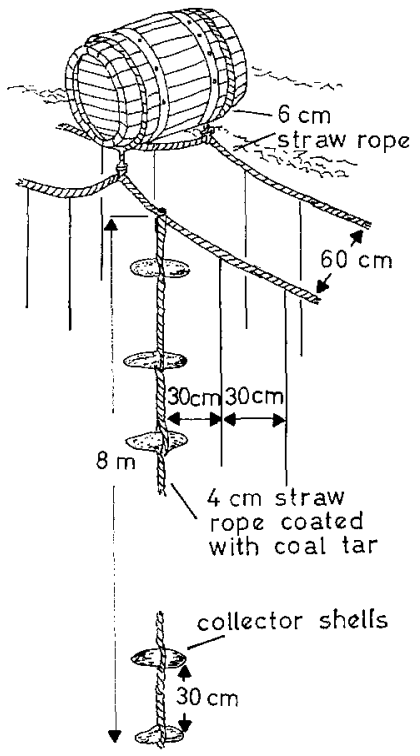

Fig. 5: Detail sketch of long-line method. (After CAHN 1950)

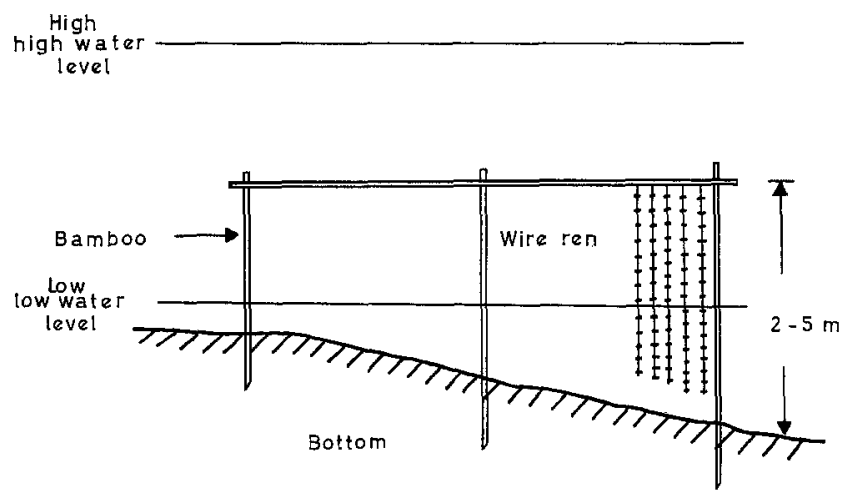

Fig. 6: Rack method for oyster farming

\section{Seasonal activities}

There are two different farming periods: one year and two year farming. In one year farming, seed oysters are transferred to the rafts in growth fields within a few weeks after collection. They can then be harvested from February through May of the next year. 
In two year farming, collectors with spats are placed on the rack in a shallow water area until the following June or July, when they are transferred to the rafts for further growth. While they are on the racks, a little growth can be expected; they reach $2.5-5 \mathrm{~cm}$ in shell height.

The detailed time courses for both farming periods are shown in Figure 7.

With one year farming, products of 5-10 $\mathrm{g}$ in shucked meat weight and with two year farming products of $10-30 \mathrm{~g}$ can be expected at each harvest in the Inland Sea area. Growth rates in northern parts of Japan are slightly lower.

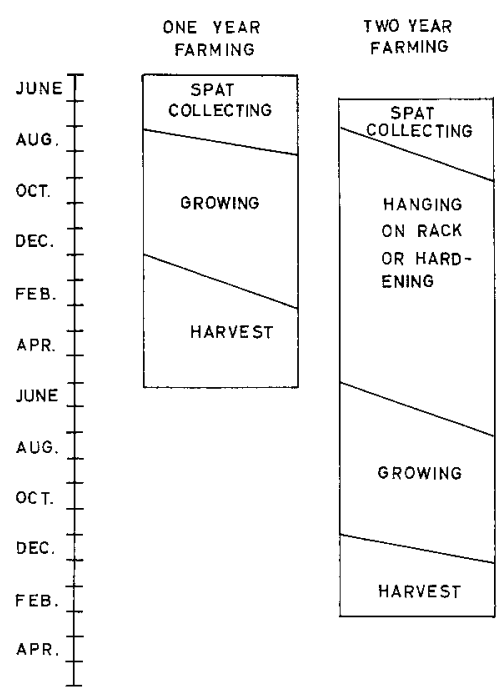

Fig. 7: Seasonal activities (time courses) of one and two year oyster farming

Farming procedures for both farming periods are almost the same except for the utilization of spats. Spat collected earlier in the season, before the middle of July, are mostly used for one year farming, because larger products can be harvested after longer growth periods. Spat collected later are used mostly for two year farming.

Frequently, seed oysters for two year farming are placed on the rafts in growth fields after one year farming products have been harvested. They are preserved on the racks and often placed in a hardening area until the rafts are ready.

In two year farming, sometimes the mortality of oysters is high (30-40\%), especially in years when the summer water temperature is high. To save oysters, the hardening procedure is effective (OGASAWARA 1962). For hardening, the young oysters are placed in relatively unsuitable environmental conditions (low salinity, fluctuating temperature, small tidal changes, long periods of air, etc.), and, on the racks, transferred into a shallow estuary area for a few months. Afterwards they are moved to the ordinary growth fields. Hardening results in a smaller sized oysters at harvest time, but in a decline in mortality (OGASAWARA 1962). 


\section{Single oyster farming}

After the one year farming harvest, a small percentage (3-5\%) of oysters which have a good shape are placed in individual net cages to be hung from rafts again (Fig. 8); 6-8 months later, these single oysters are ready for marketing. The height of their shell is then $10-20 \mathrm{~cm}$ and their meat weight $10-30 \mathrm{~g}$.

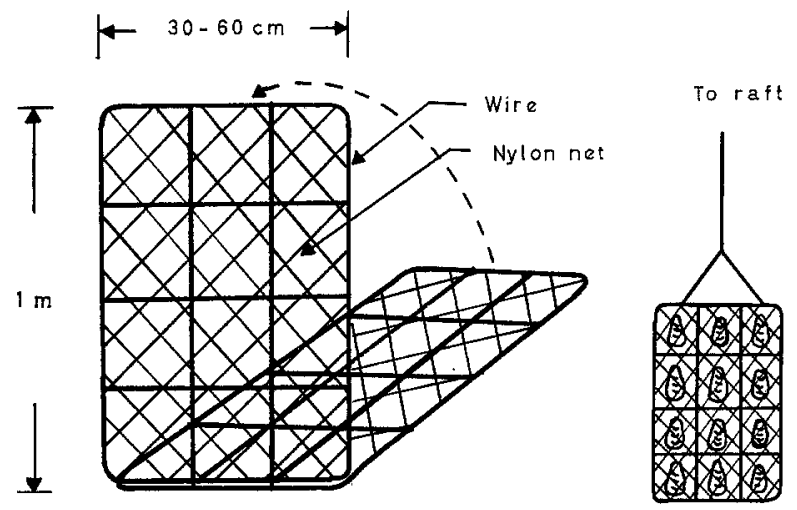

Fig. 8: Net cage for single-oyster farming

\section{Growth}

The growth rate of the oysters has a definite bearing on the economic problems of oyster farming (Fig. 9). In general, the growth rate depends on environmental conditions such as water temperature and the amount of food available. With these 2 environmental factors growth rates vary considerably. In general, growth rates are

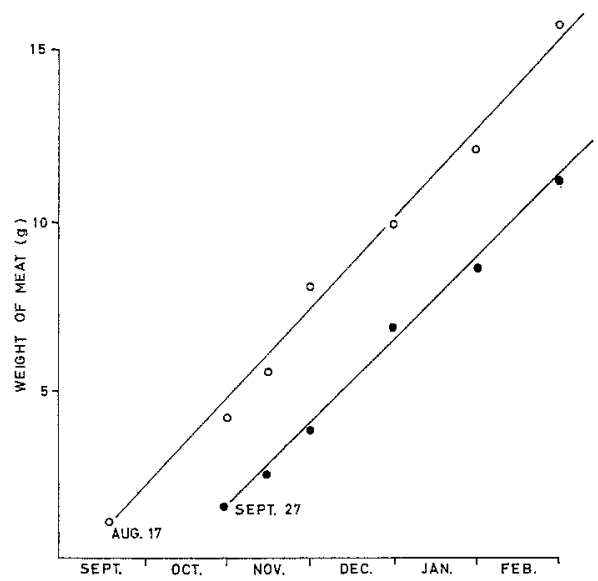

Fig. 9: Growth rate of Crassostrea gigas. (One year farming; Hiroshima) 
higher in southern (Inland Sea) than in northern parts of Japan because of the difference in water temperature. However, latitude does not always affect growth of oysters.

The growth rates of meat are not paralleled by those of the shell. Usually, the meat fattens best in autumn and winter.

\section{Harvest}

The harvest season lasts from October to May, but the products harvested after March are mostly shipped to canning and freezing plants.

A wire ren carrying reasonably well grown oysters is $30-50 \mathrm{~kg}$ in weight and, sometimes, attains $100 \mathrm{~kg}$. Therefore, harvesting necessitates a specially designed workboat. The common oyster farming boat is $6-10 \mathrm{~m}$ long, with a tall mast (usually $10 \mathrm{~m}$ or more) for lifting the wire rens and a hold for product transportation. A wire ren is hooked to the lifting wire at the top of the mast and lifted up. Then, the mast is pivoted inboard and the bottom end of the wire ren is cut. Thus, the oysters fall down on to the deck by force of their own weight.

About $90 \%$ of the oysters produced in Japan are consumed locally, they are mostly sold without shell after they have been shucked.

\section{Production and economics}

The production of oysters depends upon the locations, methods and technology, etc., and therefore difficult to describe in general terms.

As an example, the situation met in Hiroshima, Inland Sea, will be documented.

The Inland Sea is a particularly suitable place for oyster farming. Water temperature and salinity are quite suitable for growth, and enough nutrients can be supplied from the land (through rivers) to provide a high level of organic production. For these reasons, about $65 \%$ of the total oyster production of Japan comes from this area.

In a typical raft culture operation in the Inland Sea, the wire rens $(10 \mathrm{~m}$ long) produce an average of about $4 \mathrm{~kg}$ of oyster meat during the 6 to 8 months growth period. Sometimes, the production per ren reaches $10 \mathrm{~kg}$ of shucked meat. Thus, 2-4 tons of meat can be produced from a raft of 600 wire rens. This is equivalent to 20 tons of meat or 120 tons of whole oysters per acre per year (RYTHER \& BARDACH 1968).

The current wholesale price (i. e. the price for growers) of oysters in Japan is about $\$ 1.50$ per $\mathrm{kg}$ of shucked meat. Hence, the value of oysters from a single raft amounts to \$3,000-6,000, and to \$15,000-30,000 per acre (RYTHER \& BARDACH 1968).

The capital investment includes about $\$ 400$ per raft, two work boats, a modest building as work shop, warehouse and shucking plant. Under these circumstances the growers can operate business quite satisfactorily.

In comparison with other countries, the yield of oyster production in Japan is markedly higher (Table 1), because of the hanging methods and the three-dimensional 
utilization of the areas. Certainly, future marine oyster farming should be done along these lines.

Table 1

Comparison of yield rate between countries (After RYTHER \& BARDACH 1968)

\begin{tabular}{|lcc|}
\hline Countries & $\mathrm{kg} / \mathrm{ha} / \mathrm{yr}$ & $\mathrm{t} / \mathrm{acre} / \mathrm{yr}$ \\
\hline Japan (Inland Sea) & 58,000 & 23.30 \\
USA (national average) & 9 & 0.004 \\
USA (best yield) & 5,000 & 2.000 \\
France (flat oyster: national average) & 400 & 0.16 \\
France (Portuguese oyster: national average) & 935 & 0.35 \\
Australia (national average) & 150 & 0.06 \\
Australia (best yield) & 540 & 2.20 \\
\hline
\end{tabular}

\section{ENEMIES AND DAMAGES DUE TO ENVIRONMENTAL FACTORS}

\section{Enemies}

In hanging methods of oyster farming, the hanging materials harbour a specific fauna and flora. Among these are many competitors for food and space, and these competitors also interrupt the water current necessary for oysters which can lead to retarded growth.

The enemies of oysters can be classified in 4 groups: predators, competitors (fouling animals), parasites, and red tide.

Although they are rarely found in raft and long-line farming, starfish and oyster drills are relatively serious p redato $\mathrm{s}$ on rack-farmed oysters in shallow water regions. However, the damages caused by these predators are smaller than in sowing farms (GALTSOFF 1964), because it is more difficult for the predators to reach the growing oysters.

The following species of oyster drills are common in Japan: Thais tumulosa clavigera, Thais bronni, Tritonalia japonica, Rapana thomasiana and Ceratostoma burnetti. Among these species, Thais tumulosa clavigera is the most serious enemy to oysters.

Animals which have a similar or the same feeding habit as the oysters are their most serious competitors. Mytilus spp., Brachiodontes sp., tunicates (Molgula), sponges, and barnacles are typical examples of such competitors. Among these, Mytilus spp. are common, but they do not represent a serious enemy.

$\mathrm{P}$ a r a s it es such as Polydra spp., mostly Polydra ciliata, are common. Sometimes 60 to $70 \%$ of the oysters are infested by this parasite, but the damage is also not so serious (SATo 1967).

$\mathrm{R}$ ed $\mathrm{t} \mathrm{ides}$ occur in Japan mostly during spring and autumn when the water current is sluggish, usually during continuously quiet weather. Diatoms and dinoflagellates are common red tide organisms, and sometimes ciliata can be found. Many red tides do little or no damage to oysters, but dinoflagellates, especially Gymno- 
dinium spp., exert most serious effects. In the raft farming these effects can be minimized by towing the raft into an area free from the organisms before damage results. It is said that the effects become serious when the number of Gymnodinium cells increases to more than $2,000-3,000 / \mathrm{ml}$ (SATO 1967).

\section{Damages due to environmental factors}

Severe changes of water temperature, considerably above or below either the optimum or the tolerance range, cause great damage to oysters. However, oysters farmed by raft and long-line methods are less susceptible to the harmful thermal changes because they are suspended in a relatively stable environment.

Strong winds, such as typhoons, sometimes cause severe damage. Where hanging methods are used, much damage and severe losses result from destruction of supporting structures by wave action. However, long-line farmed oysters are more resistant against heavy winds and waves, and damage is not as serious. This is the main reason why long-lines are mostly used in open sea areas.

In farming areas within the influence of discharging rivers, oysters may be affected by deposits of mud and by low salinity caused by flood conditions. Such damage is most serious to young oysters. After typhoons, flood conditions are found quite frequently. Therefore, typhoons cause extremely severe damage to oyster farms in Japan.

\section{FUTURE PROBLEMS}

As shown by the yield rate, the methods and procedures for oyster farming being used in Japan should, at present, give the best results. However, there are a few problems to be solved by the industry in order to achieve further progress.

\section{Preservation of farming ground against deterioration}

Sea areas such as bays and inlets have limited capacities for oyster production. Continuous over-cropping results in deterioration of the fields and the production of oysters per unit area decreases. Sometimes the decrease in production is quite marked, and becomes a big problem for the farming industry.

The main reason for deterioration is contamination of the oysters environment via organic materials excreted by animals, by the oysters themselves, by fouling animals, and by other components of the associate fauna.

The organic material settled on the bottom interrupts the supply of food and fresh seawater to the oysters, because these materials consume the dissolved oxygen in the water, and frequently produce sulphur compounds (such as $\mathrm{H}_{2} \mathrm{~S}$ ) and ammonia compounds, which decrease the reproduction of phytoplankton and cause a decline the physiological functions of the oyster (Fujrya 1965). 


\section{Simplification of technique to save labor}

The present methods of oyster farming result in high productivity, but they are laborious. In recent years, the expanding manufacturing industries have required a large labor force, and shortage of labor has been a serious problem for primary industries such as agriculture and fisheries. Thus, simplification of techniques and mechanization of operations are urgently required. Although many difficult problems exist, they will have to be solved in order to achieve further progress in oyster industry.

\section{Protection of farming sites against pollutants}

Suitable sites for oyster production require waters containing adequate nourishment. Therefore, farming sites must be located along coastal districts.

Owing to the geography of Japan, industrial factories are also located along the coast, therefore, their pollutants easily affect fisheries, including oyster farming. This is a big problem to be solved. Some research has been carried out to evaluate the effects of pollutants on oysters (Fujia 1965).

Some wastes can be utilized, e. g., completely treated sewage for nutrients and cooling water from power plants for increasing the temperature. Therefore, it is necessary to consider problems of industrial wastes from all angles.

\section{SUMMARY}

1. The present status of oyster farming in Japan is reviewed.

2. The biology of the oyster Crassostrea gigas, a main farming species in Japan, is briefly discussed, especially in regard to spawning.

3. The farming procedures are described with special reference to suitable farming conditions, spat collecting methods, techniques and facilities for fattening (growth), and seasonal activities.

4. The yield rate of Japanese hanging methods are discussed in comparison with methods and yields of other countries.

5. Some important future problems are discussed: the need to preserve growth fields against deterioration; the need to simplify the procedures to save labor; and the need to protect farming sites from pollutants.

Acknowledgement. During the preparation of this paper, valuable information was obtained from scientists of the Hiroshima Prefectural Fisheries Experimental Station. The author wishes to gratefully acknowledge this co-operation.

\section{LITERATURE CITED}

CAHN, A. R., 1950. Oyster culture in Japan. Rep. nat. Resour. Sect. gen. HQ 134 (= Fishery Leafl. Fish Wildl. Serv. U.S. 383). 
FujIYA, M., 1965. Physiological estimation of the effects of pollutants upon aquatic organisms. In: Advances in water pollution research. Proceedings of the 2 nd International Conference held in Tokyo, 1964. Vol. 3. Ed. by E. A. Pearson. Pergamon Press, Oxford.

Galtsoff, P. S., 1964. The American oyster, Crassostrea virginica Gmelin. Fishery Bull. Fish Wildl. Serv. U.S. 64, 1-480.

Ogasawara, Y., Kobayashi, U., Okamoto, R., Furukawa, A., Hisaoka, M. \& Nogami, K., 1962. The use of the hardened seed oyster in the culture of the food oyster and its significance to the oyster culture industry. (Jap. with Engl. summary) Bull. Naikai reg. Fish. Res. Lab. 19 (103), 1-153.

RYTHER, J. H. \& BARDACH, J. E., 1968. The status and potential of aquaculture. Vol. 1. Invertebrate and algae culture. 2. Fish culture. Clearinghouse for Federal Scientific and Technical Information, Springfield, Va. (Design.: PB 177-767/768).

SAto, T., 1967. Oyster culture. Aquaculture. Koseisha-koseikaku, Tokyo.

Author's address: Dr. M. FujIYA

Nansei Regional Fisheries Research Laboratory

Maruishi, Ohno-cho, Saeki-gun, Hiroshima Pref., Japan 